\title{
Explore the Most Potential Supplier's Selection Determinants in Modern Supply Chain Management
}

\author{
Ming-Yuan Hsieh, ${ }^{1}$ Tung-Ming Yan, ${ }^{2}$ Chih-Cheng Huang, ${ }^{3}$ and Chuen-Jiuan Jane ${ }^{4}$ \\ ${ }^{1}$ Department of International Business, National Taichung University of Education, Taichung 403, Taiwan \\ ${ }^{2}$ Department of Insurance, Chao-Yang University of Technology, Taichung 413, Taiwan \\ ${ }^{3}$ Department of Leisure Recreation, National Formosa University, Yunlin County 632, Taiwan \\ ${ }^{4}$ Department of Finance \& Risk Management, Ling-Tung University, Taichung 408, Taiwan
}

Correspondence should be addressed to Ming-Yuan Hsieh; uscpawisely@hotmail.com

Received 14 June 2014; Accepted 31 July 2014; Published 28 August 2014

Academic Editor: Teen-Hang Meen

Copyright (C) 2014 Ming-Yuan Hsieh et al. This is an open access article distributed under the Creative Commons Attribution License, which permits unrestricted use, distribution, and reproduction in any medium, provided the original work is properly cited.

To increment the research reliability, validity, and representativeness, this study creatively cross-employed the factor analysis (FA) and the grey relational analysis (GRA) methods. The results of the 144 fully completed questionnaires are analyzed by FA and then these results were utilized in second questionnaires design of 15 experts. Furthermore, the results of these second questionnaires were further analyzed by GRA in order to explore the most potential supplier's selection determinants in the modern supply chain management (MSCM). Beyond a series of measurements, the measured results have induced three contributive findings: (1) the empirical interviewed industrialists reported concern that suppliers have to provide a higher material yield rate and material delivery on time rate for the qualitative increment as well as a higher supplier's gross margin ROI for the financial stabilization in MSCM; (2) the 15 experts concluded that material insurance rate is an important attribute to estimate risky assessments and the supplier's gross margin ROI and warehouse operations cost as a percentage of sales are critical elements in the financial evaluations of potential suppliers; and (3) Supplier's gross margin ROI, outbound freight cost as a percentage of sales, and material insurance rate are the three most decisive determinants in MSCM.

\section{Introduction}

Nowadays, with reference to the increased complexity in manufacture processes, some serious issues (such as delivery speed, delivery reliability, customer service, labor productivity, capacity utilization, inventory turnover, procurement costs, procurement lead time, manufacture overhead costs, product volume flexibility, production mix flexibility, manufacturing process, conformance, and product quality) have constantly appeared and then existed in each procedure of supply chain because of the two specific characteristics of supply chain management (SCM): SCM is to manage each process and activity in supply chain from material purchasing, production manufacturing, product marketing and distribution, and financial reception [1-5]. As for the essential concept of SCM, [6] it clearly defined the terms of supply chains between material suppliers and manufacturing enterprises by means of business transaction structure and assessable scopes between each other [7]. Further indicated that the relationship and network of supply chains have been existed in downstream activity from materials transaction to finished goods or services to the end-user and these processes consist of supplier transaction, manufacture process, delivery process and final client transaction, according to the three major characteristics: demand, value-adding transformation, and supply information. Continuously, [8] pointed out the four fundamental supply chain hierarchies: (1) supply within the firm boundaries, (2) supply in a dyadic relationship, (3) supply in an interorganizational chain, and (4) supply in an interorganizational network. Specifically, after the globally financial crisis, the cash-flow stress without orders and account receivable stress with slow client-payment have already become the two crucial problems in SCM. Significantly, [9] creatively addressed the academic concept 


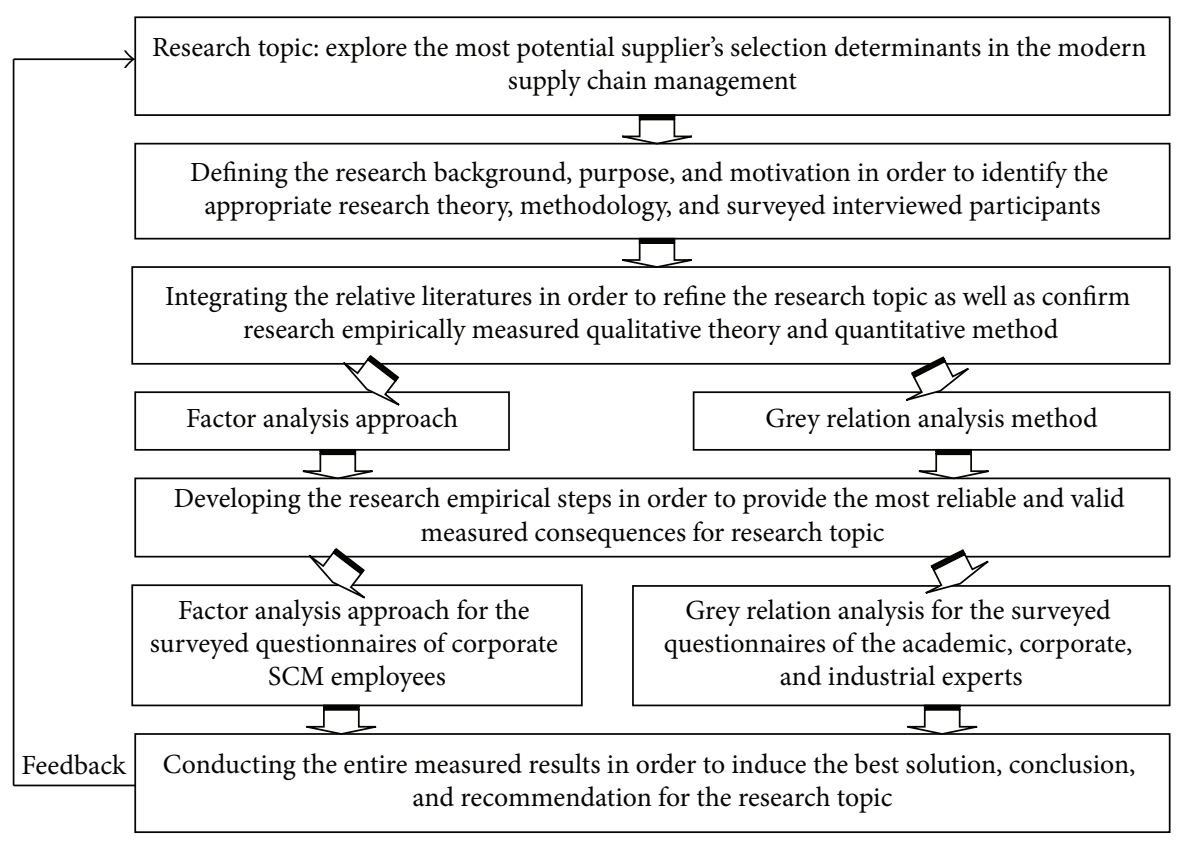

FIGURE 1: Research framework.

of financial influences from finance outlook on the patterns delivering the six comprehensive assessable criteria: financial forecasting, sales predicting, inventory strategies, delivery, supply's structure, and customer service. For this reason, the essentially functional purpose of MSCM is to effectively and efficiently stabilize the material quality and quantity of manufacturing suppliers. However, due to the rapid development of manufacturing technology and globalized society, more and more issues have commenced to appear in four dimensions [10]: (1) the modern supply chain management (MSCM); (2) evaluated factors in inventory procedure (EFIP); (3) evaluated factors in transaction-oriented procedure (EFTP); and (4) evaluated factors in customer service procedure (EFCS). In fact, a plurality of manufacture enterprises companies has commenced to face many diversified influences in MSCM under uncertain but dynamic business environment. Thus, what is the efficient and effective approach to find out the best suppliers with the less negative influence and what are the most important assessable criteria to measure suppliers have become the most crucial problem in MSCM. However, beyond making a comprehensive survey of relative literatures in MSCM fields [11-13], a lot of researches have paid numerous attentions on the production manufacture processes and human resource conduction in order to pursue the highest quality of products. Furthermore, there are a few studies to focus on the decisive influence of the potential determinants in modern SCM by means of the consolidated surveys of corporate SCM employees and the academic, corporate, and industrial experts. For this reason, this research crossemploys the analytical factor analysis (FA) and appraised grey cluster analysis (GCA) methods in order to discover the most potential supplier's selection determinants in the modern supply chain management ("MSCM") in order to maximize the corporate manufacturing performance and managerial
TABLE 1: Questionnaire validity test.

\begin{tabular}{lc}
\hline $\begin{array}{l}\text { Test number of } \\
\text { KMOMSA }\end{array}$ & Collection data appropriation for FA \\
\hline Up 0.9 & Extremely appropriated for FA approach \\
$0.8-0.9$ & Plentifully appropriated for FA approach \\
$0.7-0.8$ & Appropriated for FA approach \\
$0.6-0.7$ & Scarcely appropriated for FA approach \\
$0.5-0.6$ & Unappropriated for FA approach \\
Below 0.5 & Extremely unappropriated for FA approach \\
\hline
\end{tabular}

profits. Therefore four brief elements in research framework are going to be conducted in this research and these are (1) defining; (2) integrating; (3) developing; and (4) conducting as described in Figure 1.

\section{Relative Literatures}

As for the comprehensive analysis of financial influences in SCM, there are twenty-one critical factors of the four issue dimensions in MSCM and these are (1) EFMP issue dimension [14]: in order to recognize the quality of materials purchased from the suppliers' and the nine crucial material factors of production suppliers have to be assayed in this assessable dimension. Significantly, these are supplier's revenue growth rate (SRGR), supplier's gross margin ROI (SGMROI), supplier's sale forecast accuracy (SSFA), material yield rate (MYR), material returned rate (MRR), material delivery on time rate (MDOTR), material inspection yield rate (MIYR), material insurance rate (MIR) [15]; and material order fill rate (MOFR) [16]; (2) EFIP issue dimension [17]: in order to realize the inventory system, there are the four 
TABLE 2: Questionnaire validity test.

\begin{tabular}{lc}
\hline Cronbach's $\alpha$ & Measured results \\
\hline$\alpha>0.9$ & Extremely stable \\
$0.7<\alpha \leqq 0.9$ & Plentifully unstable \\
$0.5<\alpha \leqq 0.7$ & Stable \\
$0.4<\alpha \leqq 0.5$ & Possibly stable \\
$0.3<\alpha \leqq 0.4$ & Rarely stable \\
$\alpha \leqq 0.3$ & Extremely unstable \\
\hline
\end{tabular}

TABLE 3: Questionnaire statistic description.

\begin{tabular}{lc}
\hline Questionnaire items & Questionnaire statistic description \\
\hline Gender & Male: $67.36 \%(97)$ \\
& Female: $32.63 \%(47)$ \\
\hline \multirow{2}{*}{ Working experienced } & $0-1$ years: $27.08 \%(39)$ \\
years in SCM & $2-5$ years: $54.16 \%(78)$ \\
& $5-10$ years: $13.19 \%(19)$ \\
& Over 10 years: $5.57 \%(8)$ \\
Education & Bachelor degree: $74.3 \%(107)$ \\
& Master degree: $22.22 \%(32)$ \\
& Doctoral degree: $3.48 \%(5)$ \\
\hline
\end{tabular}

TABLE 4: Questionnaire validity test.

\begin{tabular}{lcc}
\hline $\begin{array}{l}\text { Cronbach's alpha } \\
(\alpha)\end{array}$ & $\begin{array}{c}\text { Standardized } \\
\text { Cronbach's alpha }(\alpha)\end{array}$ & Examined items \\
\hline 0.744 & 0.81 & 144 \\
\hline
\end{tabular}

TABLE 5: Questionnaire KMO-Bartlett reliability test.

\begin{tabular}{lc}
\hline Kaiser-Meyer-Olkin measure of sampling adequacy & 0.715 \\
Bartlett test of sphericity & \\
Approx. Chi-Square & 1000.879 \\
df & 210 \\
Sig. & 0.00000012 \\
\hline
\end{tabular}

critical factors to be considered in this analytical dimension: inventory turns rate (ITR), obsolete inventory rate (OIR), inventory accuracy rate (IAR); and material inventory warehouse management rate (MIWMR); (3) EFTP issue dimension [18]: in order to the stabilization of material suppliers' operation system, the five chief financial factors are explored in this dimension and these are warehouse operations cost as a percentage of sales (WOCSP), outbound freight cost as a percentage of sales (OFCOSP), product ontime shipment (POTS), material web-oriented transaction rate (MWT) [19]; and material electronic data interchange transaction rate (MEDIR) and (4) EFCS issue dimension $[20,21]$ : in order to completely understand the situation of conducting the customer feedback of suppliers, the three basic evaluated attributes are considered in this dimension: supplier's customer complaint rate (SCCR) [22], supplier's customer satisfaction rate (SCSR) [23], and supplier's customer service response time (SCSPT) [24].

Continuously, in order to completely reflect the comment of the interviewed participants' comments of SCM corporate employees on the empirically cross-analyses, this research adapted the principal component analysis of FA approach because it is able to evaluate correlation coefficient among each assessable variable in order to acquire communality between each common factor in the higher relatively analytical dimensions. Subsequently, $[25,26]$ pointed out that the analytical dimension of FA consists of two principle elements (such as common factor (or latent factor) and unique factor) resulted in two typical factor analyses (such as exploratory factor analysis (EFA) and confirmatory factor analysis (CFA) in FA approach). Particularly, [27] created the principle component analysis (PCA) [28] and principal axis factors analysis (PAFA) into FA approach to prompt two similarities of problems in FA: (1) the variable is same with two groups (e.g., the same set of measures might be taken on men and women or on treatment and control groups and then the question arises whether the two factor structures are the same) and (2) sets of variable in the one group (e.g., two test batteries might be given to a single group of subjects and questions asked about how the two sets of scores differ. Or the same battery might be given under two different conditions). Consequently, [28] addressed the typical measurement statistics process of FA approach in

$$
\begin{aligned}
& \underline{X}^{\prime}=\left(X_{1}, X_{2}, \ldots, X_{k}\right) \\
& \longrightarrow\left(P C_{1}, P C_{2}, \ldots, P C_{k}\right) \equiv\left(Y_{1}, Y_{2}, \ldots, Y_{k}\right)={\underset{\sim}{Y}}^{\prime} \\
& \text { s.t. 1: } \underset{\sim}{Y}=P^{\prime} \underset{\sim}{X}, \quad \underset{\sim}{X}=P \underset{\sim}{Y}, \\
& \text { then } X_{1}=\lambda_{11} Y_{1}+\lambda_{12} Y_{2}+\cdots+\lambda_{1 k} Y_{k} \text {; } \\
& \operatorname{Max} P C_{1}=\lambda_{11} X_{1}+\lambda_{21} X_{2}+\cdots+\lambda_{k 1} X_{k}
\end{aligned}
$$

s.t. 2: standardize intersection of variance to be 1 ;

$$
\begin{array}{ll} 
& X_{k}-\mu_{k}=\lambda_{k 1} f_{1}+\lambda_{k 2} f_{2}+\cdots+\lambda_{k m} f_{m}+e_{k} \\
\text { s.t. } & \underline{X_{k \times 1}}-\underline{\mu_{k \times 1}}=\Lambda_{k \times m} * f_{m \times 1}+\underline{e_{k \times 1}}
\end{array}
$$

Variance-Covariance matrix presents:

$$
\begin{array}{rlrl} 
& \Sigma & =\Lambda \Phi \Lambda^{\prime}+\psi, \quad \psi=\operatorname{diag}\left(\psi_{1}, \psi_{2}, \ldots, \psi_{m}\right) \\
\text { s.t. } \quad & \Phi=I_{m \times m} .
\end{array}
$$

As for the research validity, [29] induced the KaiserMeyer-Olkin measure of sampling adequacy (KMOMSA) of Kaiser-Meyer-Olkin test in surveyed measures (such as questionnaire) to identify the potential communality among each assessable criterion. Continuously, the test number of KMOMSA is supposed to be from 0 to 1 . Consequently, the test number of KMOMSA is more closed to 1 and there are more communalities between each assessable criterion which means the collected data is more suitable for FA approach as described in Table 1. In terms of the discussion of research reliability in FA approach, [30] induced that the examined numbers (Cronbach's alpha, Cronbach $\alpha$ ) of each assessable criterion in Likert's scales are able to present the stability of each assessable criterion in analytical processes of 
TABLE 6: Questionnaire ANOVA reliability test.

\begin{tabular}{lccccc}
\hline & Sum of squares & Df & Mean sum & $F$ & Sig. \\
\hline Between groups & 520.274 & 143 & 3.638 & & \\
Within groups & & & 35.486 & 33.334 & 0.00000023 \\
$\quad$ Items & 709.712 & 20 & 1.065 & \\
Residence & 3044.573 & 2860 & 1.304 & \\
$\quad$ Totality & 3754.286 & 2880 & $\mathbf{1 . 4 1 4}$ & \\
Total & $\mathbf{4 2 7 4 . 5 6 0}$ & $\mathbf{3 0 2 3}$ &
\end{tabular}

Average mean of total valid questionnaires is 5.8 .

TABLE 7: Communalities matrix of FA approach.

\begin{tabular}{lcc}
\hline Evaluated criteria & Initial & Extraction \\
\hline SRGR & 1.000 & 0.67 \\
SGMROI & 1.000 & 0.825 \\
SSFA & 1.000 & 0.789 \\
MYR & 1.000 & 0.851 \\
MRR & 1.000 & 0.708 \\
MDOTR & 1.000 & 0.826 \\
MIYR & 1.000 & 0.773 \\
MIR & 1.000 & 0.728 \\
MOFR & 1.000 & 0.699 \\
ITR & 1.000 & 0.659 \\
OIR & 1.000 & 0.709 \\
IAR & 1.000 & 0.693 \\
MIWMR & 1.000 & 0.746 \\
WOCSP & 1.000 & 0.537 \\
OFCOSP & 1.000 & 0.815 \\
POTS & 1.000 & 0.725 \\
MWT & 1.000 & 0.677 \\
MEDIR & 1.000 & 0.581 \\
SCCR & 1.000 & 0.571 \\
SCSR & 1.000 & 0.48 \\
SCSPT & 1.000 & 0.61 \\
\hline
\end{tabular}

Extraction method: Principal component analysis.

FA approach as expressed in Table 2 [31-34]. Currently, FA approach has been a mainstream in statistic measurements in diversified research fields in order to handle the complex analysis with complex factors [35-38] because there are a lot of indirectly observed potential influenced factors in the discussion of mental philosophical researches. In particular, these potential factors are supposed to be organized to common influenced factors (oblique factors) or uncommon influence factors (orthogonal factors) and based on the patterns of linear combination of these organized common factors, the multilateral analyses are discussed around the research problems $[39,40]$.

In order to truly understand the comments and messages from expert's questionnaires, this study further applied GRA method to conduct the compared pair-wise weighted measurements of each twenty-one criterion of academic, industrial, and governmental experts. Hence, as for the initiation of GRA method, [41] pioneered GRA method of the grey system theory (GST) to assay the uncertain and fuzzy collectiondata according to the concept of the Fuzzy Theory and GRA conceptual idea was that there are a series of dependences to be existed among each assessable criterion. Subsequently, the exact information of surveyed data are supposed to be grey system established between block system and white system, in order to integrate the indefinite research data to become useful research data which in-depth conduct managerial control, decision-making, and foreseeing research topic. The essential goal of GRA method of GST is to not only measure the level of relation between each appraised and affected factors under uncertain situations but to also use the tendency level among uncertain and incomplete information of each appraised and affected factor to quantify the level of relation in order to appraise the dependence or independence relations between each influenced factor in the three kinds of analytical goals $[42,43]$ :

(1) the larger the better $\left(x_{i}^{*}=\left(x_{i}^{(0)}(k)-\min x_{i}^{(0)}(k)\right) /\right.$ $\left.\left(\max x_{i}^{(0)}(k)-\min x_{i}^{(0)}(k)\right), \mathrm{LTB}\right)$;

(2) the smaller the better $\left(x_{i}^{*}=\left(\min x_{i}^{(0)}(k)-x_{i}^{(0)}(k)\right) /\right.$ $\left.\left(\max x_{i}^{(0)}(k)-\min x_{i}^{(0)}(k)\right), \mathrm{STB}\right)$;

(3) the nominal the best $\left(x_{i}^{*}=1-\left\{\left|x_{i}^{(0)}(k)-O B\right| /\right.\right.$ $\left.\left(\max \left\{\max \left[x_{i}^{(0)}(k)\right]-O B, O B-\min \left[x_{i}^{(0)}(k)\right]\right)\right\}, \mathrm{NTB}\right)$.

Furthermore, the $x_{i}^{(0)}(k)$ is computed variable of original data; the $x_{i}^{*}$ is measured variable of the data after GRA analysis; the $\min x_{i}^{(0)}(k)$ is calculated variables of the minimum of original data and the $\max x_{i}^{(0)}(k)$ is the measured variable of maximum of original data.

\section{Empirical Measurements}

3.1. First Research Step: FA Approach. In order to effectively increase the research reliability, the compared pairwise measure was utilized in the questionnaire scale of surveyed questionnaires and then the pairwise comparisons at two level are evaluated by means of the related interdependence and importance ranging from equal important (1) to extreme important (9) that follows the concept of the Likert's scale. Furthermore, the statistic description of 153 questionnaires was received, of which 144 were fully completed out of 250 questionnaires sent to corporate SCM employees by means of collected assistance from the Taiwan International Logistics 


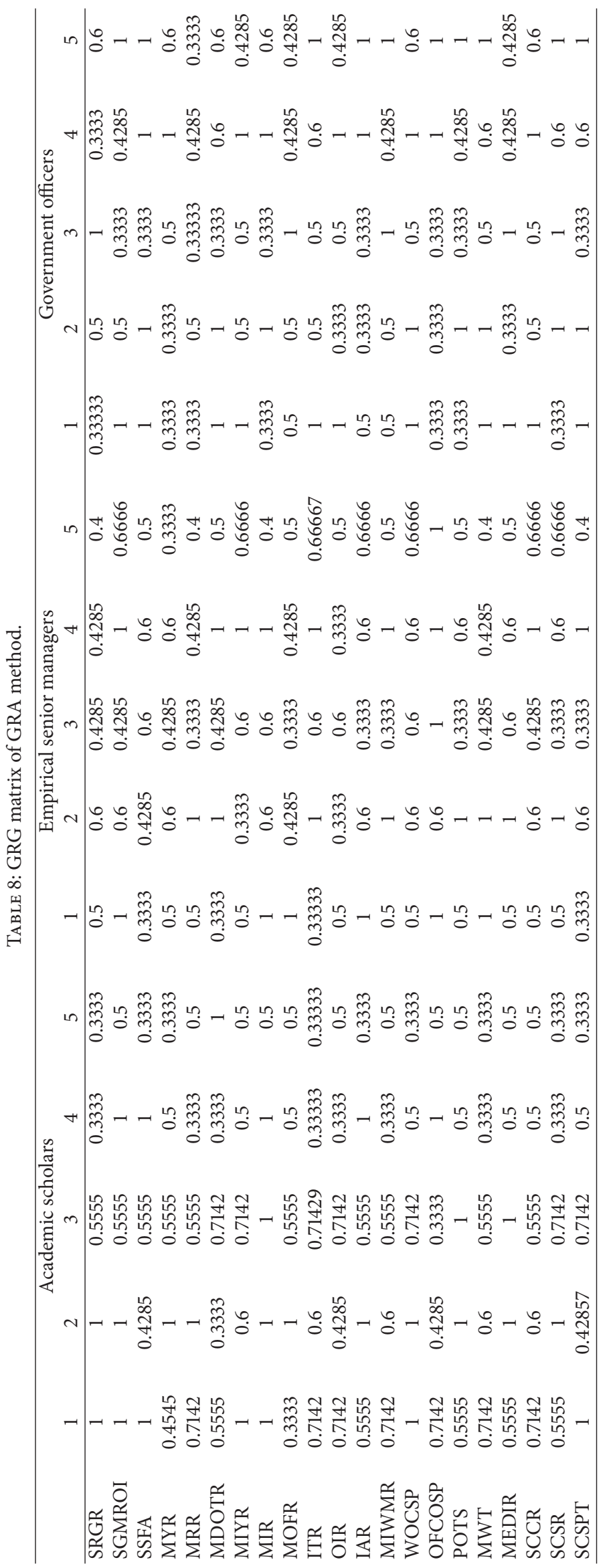


\& Supply Chain Association (TILSCO) through diversified collection manners including digital e-mail, documentary letter, and interview in person were illustrated in Table 3. Consequently, Table 4 points out that the general Cronbach's Alpha $(\alpha)$ and standardized Cronbach's alpha $(\alpha)$ of validity test results of the surveyed questionnaire were of 0.744 and 0.81 , both higher than 0.7 which means the interviewed questions in questionnaire are valid. Subsequently, the overall questionnaire response rate was $61.2 \%$. Continuously, the valid collected questionnaires were up to 144 questionnaires without any unclear answers in the compared pairwise questions of twenty-one assessable criteria and consequently, the valid questionnaires rate was $57.6 \%$. Significantly, Table 5 presents the collection of entire 144 valid questionnaires which were suited for FA approach because that KaiserMeyer-Olkin Measure of Sampling Adequacy of KMOPBartlett test of 144 valid questionnaires was 0.715 which was located at the suitable range and the significance of the KMO and Bartlett test is 0.00000012 which was smaller than 0.01 .

Subsequently, Table 6 describes the significance of the analysis of variance (ANOVA) test of reliability examination of entire 144 valid questionnaires which was 0.00000023 which was smaller than 0.01 as well and, hence, there is higher research validity in FA analytical measurements of these 144 valid questionnaires. Consequently, the communal influenced loadings of each assessable criterion in communalities matrix of principal component analysis of FA approach were completely illustrated in Table 7 . As a result, the most four top loadings were located at the most crucial evaluated factors: MYR (0.851), MDOTR (0.826), SGMROI (0.825), and OFCOSP (0.815) by means of principal component analysis of FA approach.

3.2. Second Research Step: GRA Method. In order to increase the research academic professionality and measured reliability, GRA method was further applied to deal with the secondhierarch fifteen expert's questionnaires for distinctly discovering the true comments of the surveyed questionnaire of the interviewed experts without linguistic confusion. Therefore, [42] discovered that there are the least errors of validity and reliability in the Delphi method when collected questionnaires come from, at least, over 10 professional interviewees. In addition, this research utilized the Delphi method to gather questionnaires and comments from the second-level interviewed fifteen experts who 10 of which are organized from the three professional groups. The first group represents five academic scholars with at least 10 years of extensive research in relative SCM fields and the second group comprised of five industrially senior managers who have over 10 years of working experience in the correlative SCM industries. Significantly, the last groups consisted of five government officers who have been involved in governmental SCM policies for over 10 years. Continuously, the grey relation grades (GRG) of GRA method among each twenty-one assessable criterion were presented in Table 8. Consequently, GRA of each twenty-one assessable criterion were measured according to the grey equation and described in Table 9.

3.3. Third Research Step: Integrate FA Approach and GRA Method. In order to coordinate with first-level general and
TABLE 9: GRG matrix of GRA method.

\begin{tabular}{lc}
\hline Evaluated criteria & GRG \\
\hline SRGR & 0.5564 \\
SGMROI & 0.7342 \\
SSFA & 0.6742 \\
MYR & 0.5381 \\
MRR & 0.5129 \\
MDOTR & 0.6488 \\
MIYR & 0.6562 \\
MIR & 0.7578 \\
MOFR & 0.5624 \\
ITR & 0.6597 \\
OIR & 0.5479 \\
IAR & 0.6541 \\
MIWMR & 0.6310 \\
WOCSP & 0.7076 \\
OFCOSP & 0.7051 \\
POTS & 0.6389 \\
MWT & 0.6596 \\
MEDIR & 0.6631 \\
SCCR & 0.6443 \\
SCSR & 0.6647 \\
SCSPT & 0.6384 \\
\hline
\end{tabular}

second-level expert's survey questionnaires, each potential candidate has to match each assessable subcriterion matched in each evaluated criterion through pairwise compared matrixes. Hence, in order to reflect the comparative score for the three kinds of candidates in problem solving the research issue, (2) of the synthetically comparative index numbers (SCIN) is applied to compute the comprehensively comparative related priority weight $\mathbf{w}$ (eigenvector) in the matrix and the SCIN which is defined by

$$
\begin{aligned}
& \text { Synthetically comparative index numbers (“SCIN") } \\
& =\mathrm{SCIN}_{i}=\sum_{j=1}^{n} \sum_{k=1}^{n} \mathrm{FA}_{j} \mathrm{GRA}_{k}
\end{aligned}
$$

where $\mathrm{SCIN}_{i}$ is the importance of related priority weight $\mathbf{w}$ (eigenvector) of the consolidated measurement of FA approach and GRA method for each assessable criterion $n ; \mathrm{FA}_{j}$ is the importance of related priority weight $\mathbf{w}$ (eigenvector) of the statistic measurement of FA approach for each assessable criterion $n$; and $\mathrm{GRA}_{k}$ is the importance of related priority weight $\mathbf{w}$ (eigenvector) of the statistic measurement of GRA method for each assessable criterion $n$. Subsequently, the consolidated measurement matrix is demonstrated in Table 10 based on the consolidated measurements of FA approach and GRA methods. Consequently, the first highest evaluated score of the completed SCIN of 0.6057 is located in SGMROI column and the second and third highest scores of the complete SCIN of 0.5746 and 0.5517 are located in OFCOSP and MIR. 
TABLE 10: Consolidated measurement matrix.

\begin{tabular}{|c|c|c|c|c|c|c|}
\hline & $\begin{array}{l}\text { Communality loading } \\
\text { (FA approach) }\end{array}$ & FA ranking & $\begin{array}{l}\text { Grey relation grade } \\
\text { (GRA method) }\end{array}$ & GRA ranking & SCIN & SCIN ranking \\
\hline SRGR & 0.67 & 15 & 0.5564 & 18 & 0.3728 & 18 \\
\hline SGMROI & 0.825 & 2 & 0.7342 & 2 & 0.6057 & 1 \\
\hline SSFA & 0.789 & 5 & 0.6742 & 5 & 0.5319 & 5 \\
\hline MYR & 0.851 & 1 & 0.5381 & 20 & 0.4580 & 9 \\
\hline MRR & 0.708 & 11 & 0.5129 & 21 & 0.3631 & 20 \\
\hline MDOTR & 0.826 & 3 & 0.6488 & 12 & 0.5359 & 4 \\
\hline MIYR & 0.773 & 6 & 0.6562 & 10 & 0.5072 & 6 \\
\hline MIR & 0.728 & 8 & 0.7578 & 1 & 0.5517 & 3 \\
\hline MOFR & 0.699 & 12 & 0.5624 & 17 & 0.3931 & 13 \\
\hline ITR & 0.659 & 16 & 0.6597 & 8 & 0.4347 & 12 \\
\hline OIR & 0.709 & 10 & 0.5479 & 19 & 0.3885 & 15 \\
\hline IAR & 0.693 & 13 & 0.6541 & 11 & 0.4533 & 10 \\
\hline MIWMR & 0.746 & 7 & 0.6310 & 16 & 0.4707 & 7 \\
\hline WOCSP & 0.537 & 20 & 0.7076 & 3 & 0.3800 & 17 \\
\hline OFCOSP & 0.815 & 4 & 0.7051 & 4 & 0.5746 & 2 \\
\hline POTS & 0.725 & 9 & 0.6389 & 15 & 0.4632 & 8 \\
\hline MWT & 0.677 & 14 & 0.6596 & 9 & 0.4465 & 11 \\
\hline MEDIR & 0.581 & 18 & 0.6631 & 7 & 0.3852 & 16 \\
\hline SCCR & 0.571 & 19 & 0.6443 & 13 & 0.3679 & 19 \\
\hline SCSR & 0.48 & 21 & 0.6647 & 6 & 0.3190 & 21 \\
\hline SCSPT & 0.61 & 17 & 0.6384 & 14 & 0.3894 & 14 \\
\hline
\end{tabular}

\section{Conclusion}

According to the swift development of manufacture technologies, there are a lot of crucial factors to affect the corporate supplier's selection under the lowest risks and highest profits consideration. Hence, this study firstly employed FA approach to conduct the first-level 144 empirical questionnaires and then applied GRA method to assay the secondlevel 15 expert's questionnaires in order to explore the most potential supplier's selection determinants in MSCM due to the increment of the research reliability, validity, and representativeness. Significantly, after making a comprehensive survey of relative literatures as well as conducting a series of hierarchically evaluated measurements, the measured consequences have distinctly induced the three contributive findings: (1) the empirical interviewed industrialists reported concern that suppliers have to provide not only a higher material yield rate (MYR) and material delivery on time rate (MDOTR) for the stably qualitative increment in MSCM but must also provide higher supplier's gross margin ROI (SGMROI) for the financial stabilization in MSCM; (2) the academic, corporate executive, and governmental experts concluded that material insurance rate (MIR) is an important attribute to estimate risky assessments of suppliers and the supplier's gross margin ROI (SGMROI) and warehouse operations cost as a percentage of sales (WOCSP) are critical elements in the financial evaluations of potential suppliers and (3) supplier's gross margin ROI (SGMROI), outbound freight cost as a percentage of sales (OFCOSP), and material insurance rate (MIR) are the three most decisive determinants in MSCM by weighting the results from the two sets of questionnaires. According to the expert's comments of surveyed questionnaire, the manufacturing enterprises have commenced to suffer the financial stress from not only suppliers but also customers after the 2008 global finance crisis because the suppliers are not willing to provide the stabilized material supply chain and the customers are not willing to offer a stable procurement demand orders or paying over six months check for these orders.

\section{Conflict of Interests}

The authors declare that there is no conflict of interests regarding the publication of this paper.

\section{References}

[1] E. Deutskens, K. de Ruyter, and M. Wetzels, "An assessment of equivalence between online and mail surveys in service research," Journal of Service Research, vol. 8, no. 4, pp. 346-355, 2006.

[2] P. W. Balsmeier and W. J. Voisin, "Supply chain management: a time-based strategy," Industrial Management, vol. 38, no. 5, pp. $24-27,1996$.

[3] B. M. Beamon, "Supply chain design and analysis: models and methods," International Journal of Production Economics, vol. 1, no. 4, pp. 281-294, 1998. 
[4] M. Christopher, Logistics and Supply Chain Management: Strategies for Reducing Costs and Improving Services, Pitman, London, UK, 1992.

[5] M. Christopher, Logistics and Supply Chain Management, Financial Times Pitman, London, UK, 2nd edition, 1998.

[6] M. C. Cooper and M. E. Lisa, "Characteristics of supply chain management and implication for purchasing and logistics strategy," International Journal of Logistics Management, vol. 4, no. 2, pp. 21-58, 1993.

[7] F. Chen, Z. Drezner, J. K. Ryan, and D. Simchi-Levi, "Quantifying the bullwhip effect in a simple supply chain: the impact of forecasting, lead times, and information," Management Science, vol. 46, no. 3, pp. 436-443, 2000.

[8] L. M. Ellram, W. L. Tate, and C. R. Carter, "Product-processsupply chain: an integrative approach to three-dimensional concurrent engineering," International Journal of Physical Distribution and Logistics Management, vol. 37, no. 4, pp. 305-330, 2007.

[9] R. N. Kostoff and E. Geisler, "Strategic management and implementation of textual data mining in government organizations," Technology Analysis and Strategic Management, vol. 11, no. 4, pp. 493-525, 1999.

[10] P. Lee, “The 5 keys to supply chain success," CIO Magazine, 2001.

[11] S. Croom, P. Romano, and M. Giannakis, "Supply chain management: an analytical framework for critical literature review," European Journal of Purchasing and Supply Management, vol. 6, no. 1, pp. 67-83, 2000.

[12] L. Lapide, "What about measuring supply chain performance?" 2000.

[13] R. Metters, "Quantifying the bullwhip effect in supply chains," Journal of Operations Management, vol. 15, no. 2, pp. 89-100, 1997.

[14] M. Christopher and H. Lee, "Mitigating supply chain risk through improved confidence," International Journal of Physical Distribution \& Logistics Management, vol. 34, no. 3, pp. 388-396, 2004.

[15] A. Norrman and U. Jansson, “Ericsson's proactive supply chain risk management approach after a serious sub-supplier accident," International Journal of Physical Distribution \& Logistics Management, vol. 34, no. 3, pp. 434-456, 2004.

[16] L. C. Giunipero and R. A. Eltantawy, "Securing the upstream supply chain: a risk management approach," International Journal of Physical Distribution \& Logistics Management, vol. 34, no. 2, pp. 698-713, 2004.

[17] P. K. Oliver and M. D. Webber, "Supply-chain management: logistics catches up with strategy," in Logistics: The Strategic Issues, M. Christopher, Ed., pp. 63-75, Outlook, Booz, Allen and Hamilton, Chapman Hall, London, UK, 1992.

[18] P. C. Brewer and T. W. Speh, "Using the balanced scorecard to measure supply chain performance," Journal of Business Logistic, vol. 21, no. 1, pp. 75-93, 2000.

[19] D. L. Simchi, P. Kaminsky, and E. L. Simchi, Designing and Managing the Supply Chain, McGraw-Hill, Boston, Mass, USA, 2000.

[20] G. Zäpfel and B. Piekarz, Supply Chain Controlling, Überreuter, Vienna, Austria, 1996.

[21] K. B. Hendricks and V. R. Singhal, "What is the real cost of your supply chain problems?” Supply Chain \& Logistics Journal, vol. 4, no. 4, pp. 1-42, 2001.

[22] J. B. Hulihahn, "International supply chain management," International Journal of Physical Distribution and Materials Management, vol. 15, no. 1, pp. 51-66, 1985.
[23] B. J. LaLonde, “The costs of functional shiftability," Supply Chain Management Review, pp. 9-10, 1998.

[24] B. J. LaLonde and L. P. Terrance, "Issues in supply chain costing," The International Journal of Logistics Management, vol. 7, no. 1, pp. 5-8, 1996.

[25] H. H. Harman, Modern Factor Analysis, University of Chicago Press, 1976.

[26] W. F. Velicer, "Determining the number of components from the matrix of partial correlations," Psychometrika, vol. 41, no. 3, pp. 321-327, 1976.

[27] R. B. Darlington, Factor Analysis, 2004.

[28] J. D. Brown, Principal Components Analysis and Exploratory Factor Analysis-Definitions, Differences and Choices, JALT Testing \& Evaluation SIG Newsletter, Shiken, China, 2012.

[29] H. F. Kaiser, "An index of factorial simplicity," Psychometrika, vol. 39, no. 1, pp. 31-36, 1974.

[30] L. J. Cronbach, "Coefficient $\alpha$ and the internal structure of tests," Psychometrika, vol. 16, no. 3, pp. 297-334, 1951.

[31] N. Schmitt, "Uses and abuses of coefficient alpha," Psychological Assessment, vol. 8, no. 4, pp. 350-353, 1996.

[32] R. Zinbarg, I. Yovel, W. Revelle, and R. McDonald, "Estimating generalizability to a universe of indicators that all have an attribute in common: a comparison of estimators for alpha," Applied Psychological Measurement, vol. 30, pp. 121-144, 2006.

[33] W. Revelle and R. E. Zinbarg, "Coefficients alpha, beta, omega, and the glb: comments on Sijtsma," Psychometrika, vol. 74, no. 1, pp. 145-154, 2009.

[34] N. Ritter, "Understanding a widely misunderstood statistic: Cronbach's alpha," in Proceeding of the Southwestern Educational Research Association (SERA) Conference, New Orleans, La, USA, 2010.

[35] D. Love, D. K. Hallbauer, A. Amos, and R. K. Hranova, "Factor analysis as a tool in groundwater quality management: two southern African case studies," Physics and Chemistry of the Earth, vol. 29, no. 15-18, pp. 1135-1143, 2004.

[36] J. Ruscio and B. Roche, "Determining the number of factors to retain in an exploratory factor analysis using comparison data of known factorial structure," Psychological Assessment, vol. 24, no. 2, pp. 282-292, 2012.

[37] L. E. Garrido, F. J. Abad, and V. Ponsoda, "A new look at Horn's parallel analysis with ordinal variables," Psychological Methods, vol. 18, no. 4, pp. 454-474, 2013.

[38] N. Ritter, "A comparison of distribution-free and nondistribution free methods in factor analysis," in Proceedings of the Southwestern Educational Research Association (SERA) Conference, ED529153, New Orleans, Lo, USA, 2012.

[39] M. G. R. Courtney, "Determining the number of factors to retain in EFA: using the SPSS R-Menu v2.0 to make more judicious estimations," Practical Assessment, Research and Evaluation, vol. 18, no. 8, pp. 24-57, 2013.

[40] R. T. Warne and R. Larsen, "Evaluating a proposed modification of the Guttman rule for determining the number of factors in an exploratory factor analysis," Psychological Test and Assessment Modeling, vol. 56, pp. 104-123, 2014.

[41] D. Ju-Long, "Control problems of grey systems," Systems \& Control Letters, vol. 1, no. 5, pp. 288-294, 1982.

[42] J. Deng, "Introduction to grey system theory," Journal of Grey System, vol. 1, pp. 1-24, 1989.

[43] J. W. K. Chan and T. K. L. Tong, "Multi-criteria material selections and end-of-life product strategy: grey relational analysis approach," Materials and Design, vol. 28, no. 5, pp.15391546, 2007. 


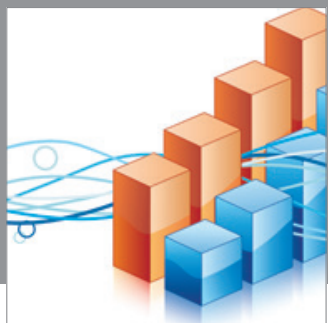

Advances in

Operations Research

mansans

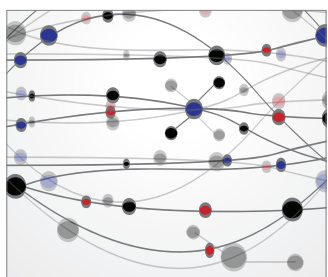

The Scientific World Journal
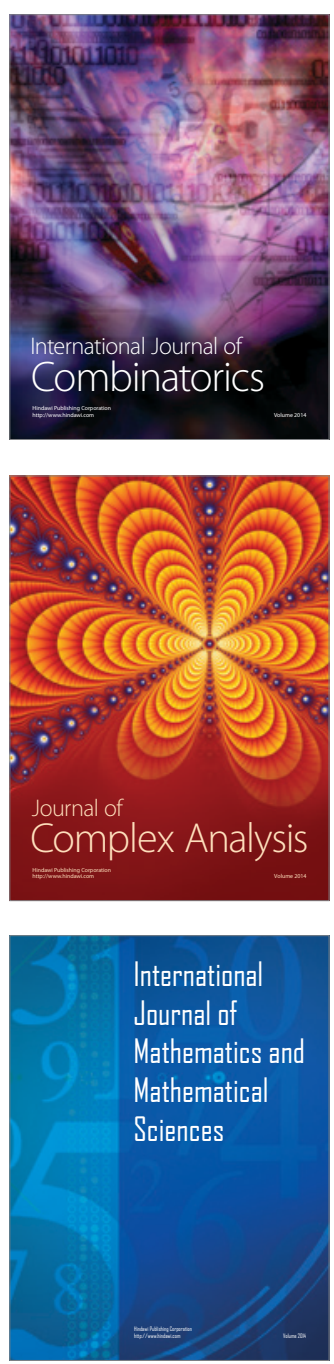
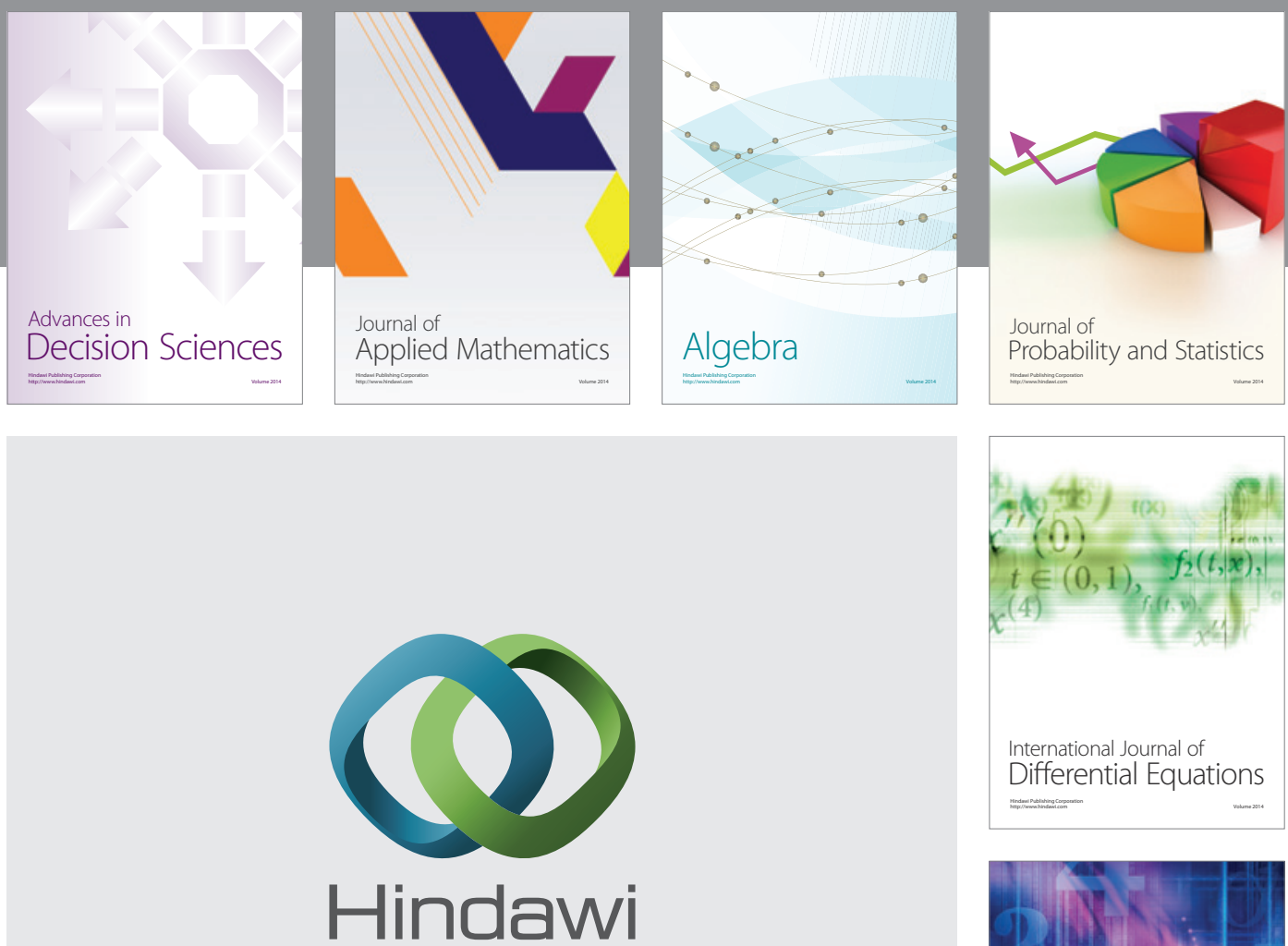

Submit your manuscripts at http://www.hindawi.com
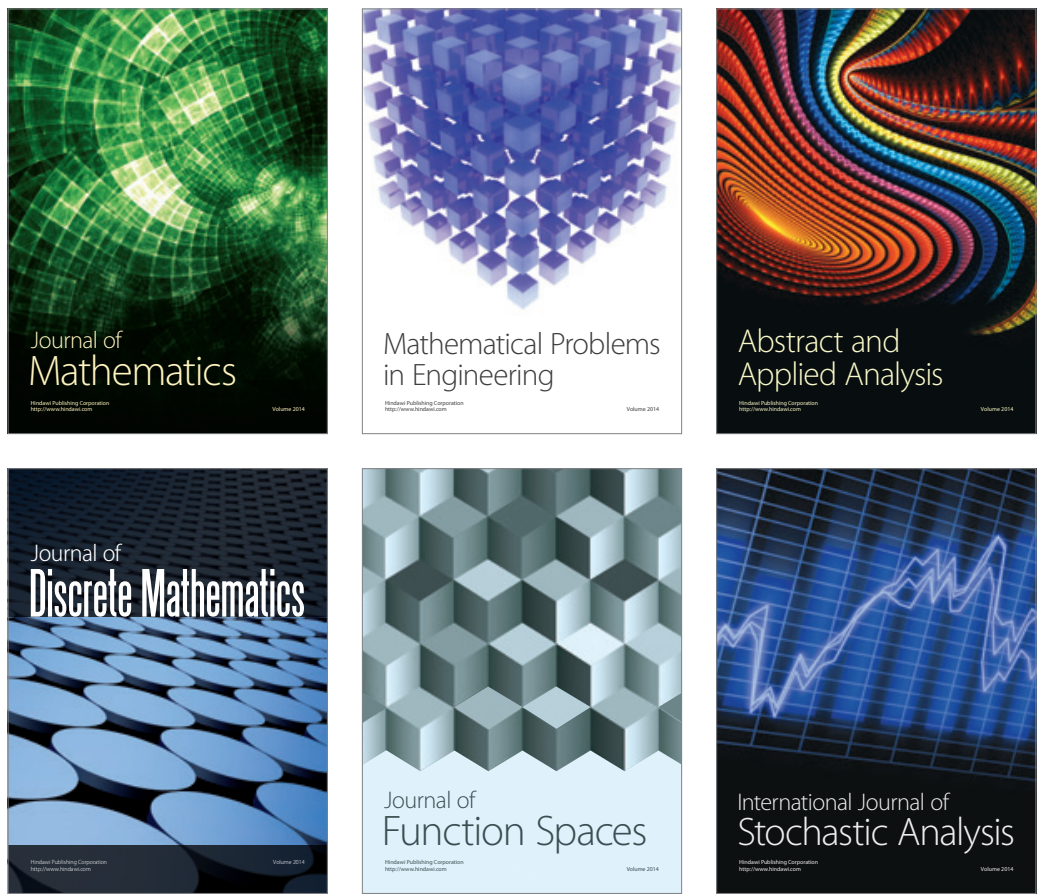

Journal of

Function Spaces

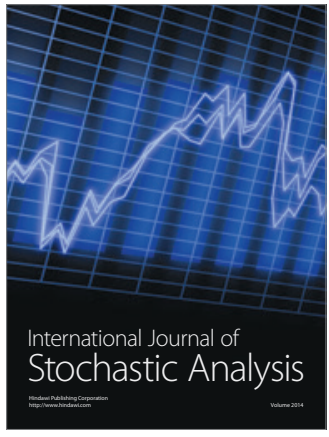

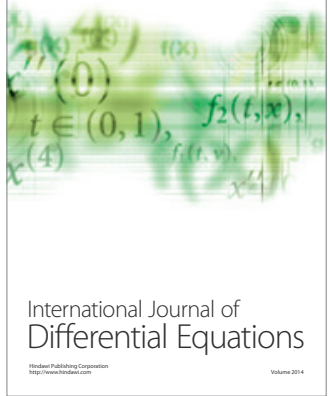
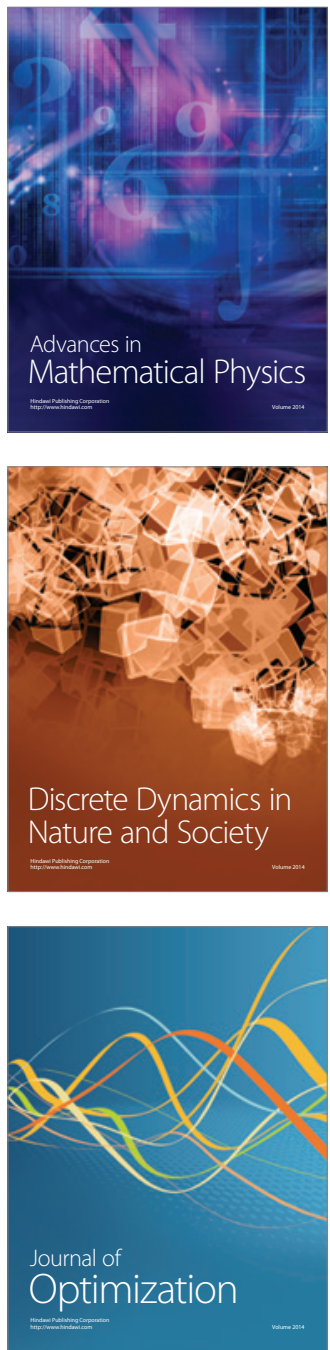